\title{
ANALYSIS OF DEEP STRESS FIELD USING WELL LOG AND WELLBORE BREAKOUT DATA: A CASE STUDY IN CRETACEOUS OIL RESERVOIR, SOUTHWEST IRAN
}

\author{
Mohammad ABDIDEH ${ }^{*}$, Sina ALISAMIR \\ Department of Petroleum Engineering, Omidiyeh Branch, Islamic Azad University, Omidiyeh, Iran
}

Received 24 July 2018; accepted 15 November 2018

\begin{abstract}
To identify the wellbore instability of Bangestan oil reservoir in the southwestern Iran, the direction and magnitude of stresses were determined using two different methods in this study. Results of injection test and analysis of wellbore breakouts were used to verify the accuracy of the stress profiles. In this study the Bartoon method, which using the breakout angle and strength of rock, was used. In addition, the ability of artificial neural network to estimate the elastic parameters of rock and stress field was used. The output of the neural network represents a high accuracy in the estimation of the desired parameters.

In addition, the Mohr-Coulomb failure criterion was used to verify stress profiles. Estimated stresses show relative compliance with the results of injection test and Barton method. The required minimum mud pressure for preventing shear failures was calculated by using the Mohr-Coulomb failure criterion and the estimated stress profiles. The results showed a good compliance with failures which have been identified in the caliper and image logs. However, a number of noncompliance is observed in some depth. This is due to the concentration of fractures, collisions between the drill string and the wellbore wall, as well as swab and surge pressures. The stress mode is normal and strike-slip in some depth based on the estimated stress profiles. According to direction of breakouts which is clearly visible in the caliper and image logs, the minimum and maximum horizontal stresses directions were NW-SE and NE-SW, respectively. Thses directions were consistent with the direction of regional stresses in the Zagros belt.
\end{abstract}

Keywords: stress field, wellbore breakout, failure criteria, image log.

\section{Introduction}

The direction and magnitude of in situ stresses in great depth is special importance for geologists and engineers, especially petroleum engineers. Stresses around wellbores (whether natural or induced by different operations such as drilling, production and fluid injection operations) have significant impact on the geomechanical behavior, stability and design of the trajectory of the wellbores, optimizing perforation or completion design, and production planning. In the past few decades, many studies have been conducted to measure these stresses and their impact or importance in the development of the oil industry (Barton, Zoback, \& Burns, 1988; Aadnøy, 1990; Chen, Tan, \& Haberfield, 1996; Morita et al., 1996; Brudy \& Zoback, 1999; Akbar Ali et al., 2003; Klimentos (Schlumberger), 2005; Al-Ajmi, 2006; Mohiuddin et al., 2007; Najibi et al., 2015; Azadpour, Shad Manaman, Kadkhodaie-Ilkhchi, \& Sedghipour, 2015; Khosravanian \& Aadnoy, 2016;
Kidambi \& Kumar, 2016; Anemangely, Ramezanzadeh, Tokhmechi, Molaghab, \& Mohammadian, 2018a).

In situ stresses are usually expressed in terms of a tensor of six components. However, in of oil fields studies, the stresses are determined only for three principal components of the stress: a vertical component $\left(\sigma_{\mathrm{v}}\right)$, and two minimum and maximum horizontal stress components $\left(\sigma_{\mathrm{H}}\right.$ and $\left.\sigma_{\mathrm{h}}\right)$. Accordingly, a number of direct and indirect methods (empirical equations) have been presented to determine the magnitude of stresses in oil reservoirs in great depth. However, the principal horizontal stresses, especially $\sigma_{\mathrm{H}}$, are still major challenge to determine in geomechanical oil field studies (Zobac et al., 2003).

Direct methods for measuring stress are hydraulic fracture, leak off, micro-fracture and injection test (Haimson \& Fairhurst, 1967; Gaarenstroom, Tromp, De Jong, \& Brandenburg, 1993; Economides, Oligney, \& Valko, 2000). Because of high cost and difficulty of implementation (especially in great depths), these tests are rarely conducted

*Corresponding author. E-mail: m.abdideh@yahoo.com 
and may not be successful in some cases. In addition, the results of these tests do not provide the continuous curve for the in situ stress state.

Indirect methods such as Zoback and Healy (1984) and poroelastic are alternative methods to determine profiles of stresses with respect to depth (Iverson, 1996; Zoback et al., 2003). The results of these methods need to be verified because of the complexity of tectonic conditions in different parts of the earth's crust. The results of direct tests are used to verify the accuracy of estimated values. Other methods are to study the presence or absence of tensile and shear failures around wellbore and drilling fluid pressure (Zoback et al., 2003).

As the overburden stress increases with depth progressively, the stresses are expected to be normal at usual depths of oil reservoirs $\left(\sigma_{v} \geq \sigma_{H} \geq \sigma_{h}\right)$. However, in some cases, the tectonic conditions such as faulting and folding may be changed stress state to reverse mode or strike-slip mode.

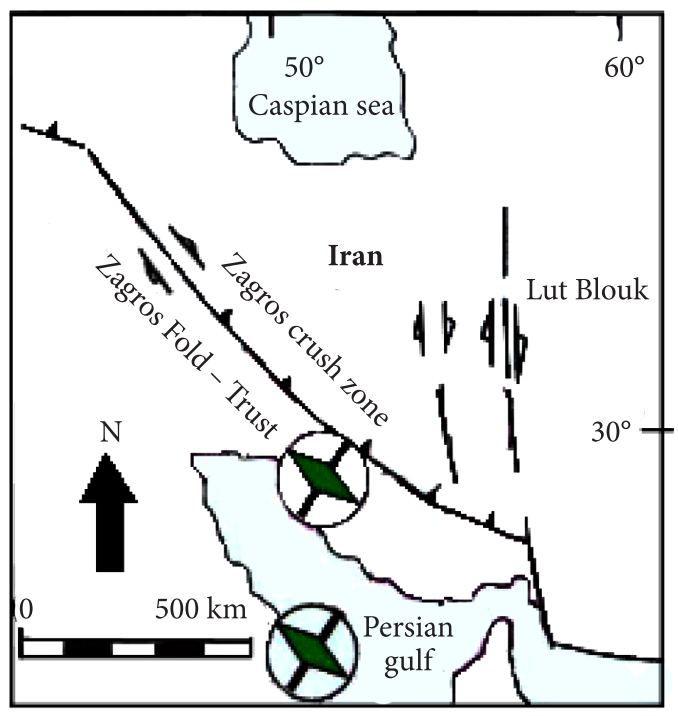

Figure 1. Orientation of regional stresses in the Zagros FoldTrust belt based on breakouts and drilling induced fracture data (Akbar \& Sapru, 1994)
In this study, the stress profiles were calculated for several wellbores of Bangestan reservoir, located in an oilfield in southwestern Iran. Because the studied field is located in the Zagros thrust-fold belt, the reverse faults and fault propagation folds may cause a reverse stress regime in great depth. The horizontal stresses were estimated using Zoback and Healy method, which is based on Anderson's (1951) faulting theory. The poroelastic method which is commonly used in petroleum studies was also used to calculate the stress magnitude. The density logs were used to calculate the vertical stress for all the wellbores.

Iin this study, the geomechanical data such as Poisson ratio, Young's modulus and uniaxial compressive strength were calculated using empirical equations. The equations are mostly based on petrophysical data such as slowness of shear and compression waves ( $\Delta t s$ and $\Delta t c$ ) density (RHOB) and neutron (NPHI) logs. Accuracy of the results was verified using laboratory data.

\section{Geology setting}

Located in a flat plain, the studied field has no surface outcrop. This field, which is located in Zagros thrust-fold belt, has the same trend as the Zagros, namely the North West-South East (Figure 1). Anticline axis shows torsion to the north at the two ends. Northern limb is steeper than southern limb, so that the latter has a dip of 7 degrees, while the dip of the former reaches a maximum of 9 degrees in the central parts. No fault has been detected in this field (Figure 2).

The Bangestan limestone unit consists of two formations, Ilam and Sarvak. The latter overlies the Kazhdumi Formation with parallel discontinuities, while it has a boundary with angular discontinuities with the Ilam Formation. The Gurpi Formation also covers the Ilam Formation with parallel discontinuities. The Sarvak Formation is part of middle Cretaceous calcareous rocks. Lithology of the Ilam Formation consists of limestone rocks with a regular stratification, in which there are thin interlayers of shale in some intervals.

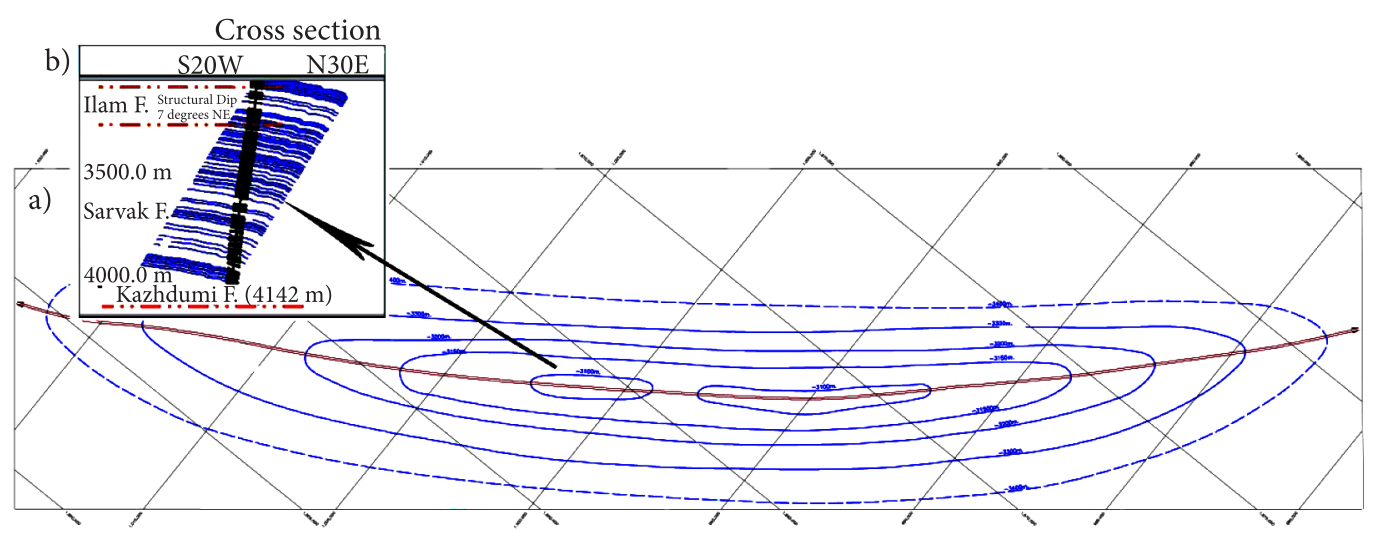

Figure 2. Top of the Ilam formation and torsion of axis anticline in the studied field, b) Structural cross-section using bedding dips data. A structural dip of 7 degrees NE is the most representative of the whole interval of the Ilam and 9 degrees NE the Sarvak Formation dip of northern limb in internal of studied field 
Considering the history of the Zagros belt, most oil fields in this region are more or less crushed, with multiple fracture sets. Based on the image logs, a set of fracture was detected in the Ilam Formation, and two sets of fracture in the Sarvak Formation (Figure 3).

Based on the alternating permeable and impermeable layers, the Bangestan reservoir is divided into nine zones, of which three zones are located in the Ilam Formation (1-3) and the rest belongs to Sarvak Formation (4-9).

\section{Methods and materials}

\subsection{Magnitude of horizontal stress}

As was previously mentioned, the vertical stress was calculated using density logs based on the following relation. For points where there are no data, density is assumed to be about $2.5 \mathrm{gr} / \mathrm{cm}^{3}$.

$$
\sigma_{V}=\int_{0}^{z} \rho_{b}(z) g d z \cong \bar{\rho}_{b} g z
$$

where $\rho_{b}(z)$ - the formation density as a function of depth, $\bar{\rho}_{b}$ - mean overburden density, $g$ - the gravitational acceleration constant and $z$ - depth.

Although it is not possible to simply measure the stress, it could be inferred or modeled from other measurements. The minimum horizontal stress can be easier determined compared to the maximum horizontal stress, because the latter is generally determined using appropriate models and is confirmed using evidence such as wellbore breakout and induced tensile fractures.

Zoback and Healy method is a simple and rapid method for calculating horizontal stresses. Using this method, the stress profiles were calculated for both reverse and normal conditions.

Normal Faulting : $\frac{\sigma_{1}}{\sigma_{3}}=\frac{\sigma_{v}-P_{p}}{\sigma_{h}-P_{p}} \leq\left[\left(\mu^{2}+1\right)^{1 / 2}+\mu\right]^{2}$;

Reverse Faulting : $\frac{\sigma_{1}}{\sigma_{3}}=\frac{\sigma_{H}-P_{p}}{\sigma_{V}-P_{p}} \leq\left[\left(\mu^{2}+1\right)^{1 / 2}+\mu\right]^{2}$,

where $\mu$-coefficient of friction and $P_{P}$ - Pore pressure.

The parameter $P p$ is obtained from well test methods such as RFT. These methods are not related to lithology and can be done in a variety of lithology.

Coefficient of friction, which ranges from 0.6 to 1 , was assumed to be 0.6 in this study (Byerlee, 1978). The Coefficient of friction parameter is selected based on the lithology type. The dominant lithology in the studied oilfield is limestone.

Another method used to calculate the horizontal stresses is based on the poroelastic theory. In a tectonically active basin, tectonic stresses and strains arise from tectonic plate movement. If tectonic strains are applied to rock formations, these strains add a stress component in an elastic rock. The poroelastic horizontal strain model, takes tectonic strains into account, and therefore accommodates anisotropic horizontal stresses (Blanton \& Olson, 1999).

$$
\begin{aligned}
& \sigma_{h}=\frac{v}{1-v} \sigma_{v}-\frac{v}{1-v} \alpha p_{p}+\alpha p_{p}+\frac{E}{1-v^{2}} \varepsilon_{y}+\frac{v E}{1-v^{2}} \varepsilon_{x} ;(4) \\
& \sigma_{H}=\frac{v}{1-v} \sigma_{v}-\frac{v}{1-v} \alpha p_{p}+\alpha p_{p}+\frac{E}{1-v^{2}} \varepsilon_{x}+\frac{v E}{1-v^{2}} \varepsilon_{y},(5)
\end{aligned}
$$
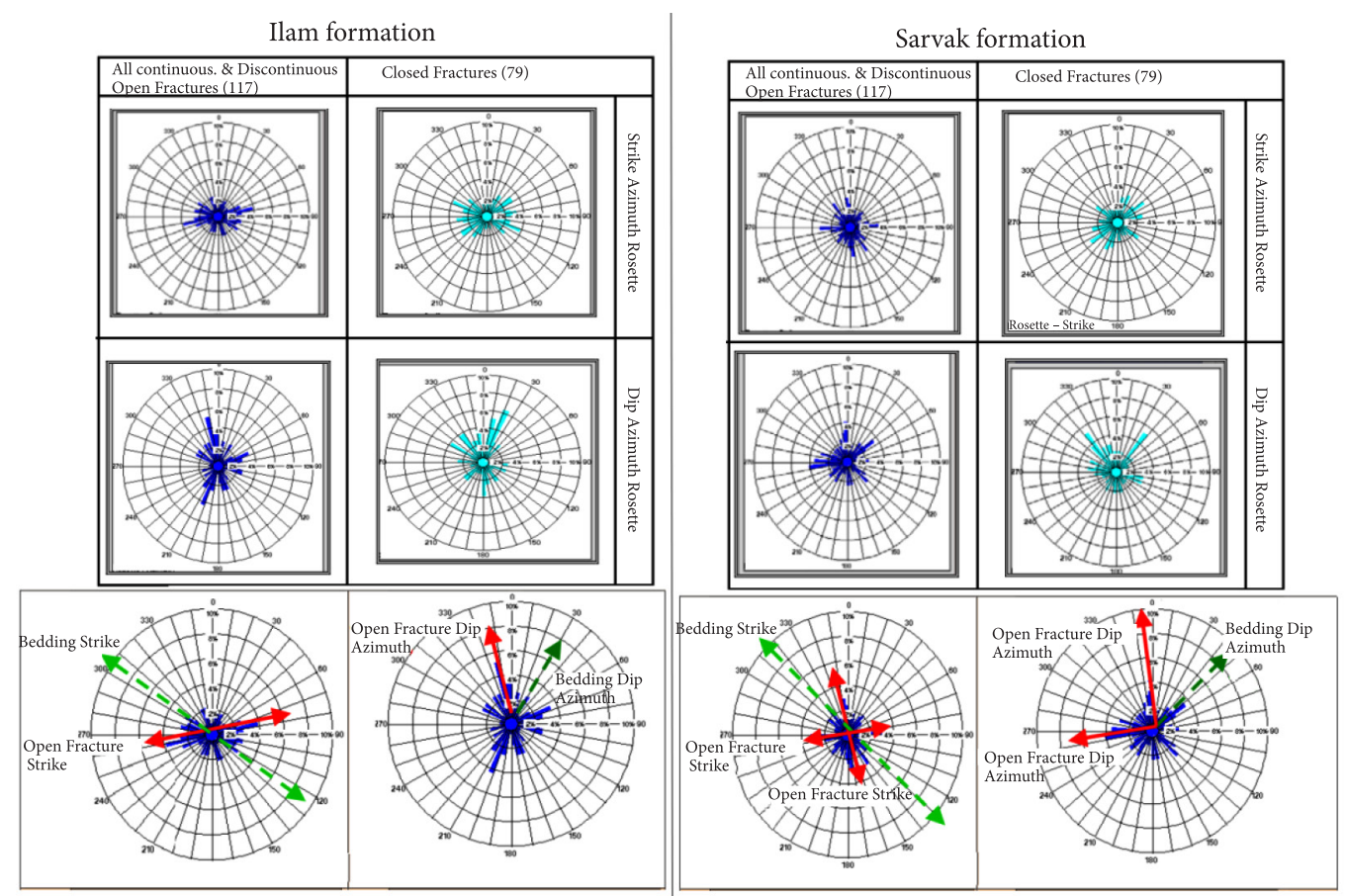

Figure 3. Statistical plots of dip attributes of bedding, all open fractures and closed fractures in Ilam and Sarvak Formation. Open fractures and bedding dip attributes showing that the fractures strike 44 degrees to the bedding 
where $E$ - Young's modulus, $v$ - Poisson's ratio, $\alpha$ - Biot's constant, $\varepsilon_{x}$ and $\varepsilon_{y}-$ strain toward minimum and maximum horizontal stresses, respectively.

The Biot's constant varies from near zero for very stiff zero-porosity rocks, towards a value of near-unity for many porous rocks in shallow sedimentary basins. According to the studies conducted in the area, $\alpha=1$. In addition, based on available evidence and the history of the region, the ratio $\varepsilon_{x} / \varepsilon_{y}$ was considered equal to 1.5 .

For accurate selection of the parameters $\varepsilon_{x}$ and $\varepsilon_{y}$, sensitivity image logos are made. Some of the phenomena such as the break out that are visible on image logos are used.

The static Young's modulus and the Poisson's ratio represent the basic inputs for this method. Calculation static elastic constants, is not possible directly. Dynamic elastic constants can be calculated easily using petrophysical logs. However, these dynamic constants are systematically different from the equivalent static values. Using worldwide database of laboratory and field measurements on oilfield, a number of methods presented to convert dynamic elastic constants to their static equivalents using a variety of proprietary. Assuming elastic isotropy, the fallowing equations were used to calculate the dynamic elastic properties:

$$
\begin{gathered}
v_{d y n}=\frac{1 / 2\left(\frac{\Delta t_{s}}{\Delta t_{c}}\right)^{2}-1}{\left(\frac{\Delta t_{s}}{\Delta t_{c}}\right)^{2}-1} ; \\
E_{d y n}=\frac{\rho_{b}\left[3-4\left(\frac{\Delta t_{c}}{\Delta t_{s}}\right)^{2}\right]}{\Delta t_{s}{ }^{2}-\Delta t_{c}{ }^{2}},
\end{gathered}
$$

where $v_{d y n}$ - dynamic Poisson's ratio and $E_{d y n}-$ dynamic Young's modulus.

Generally, there is no direct relationship between the static and dynamic Poisson ratios. Therefore, these two quantities are usually considered to be equal. The following relation, which shows similar results with laboratory data of the rock samples, was used to convert dynamic and static Young's modulus (Najibi, 2012; Anemangely et al., 2018a).

$$
E_{\text {sta }}=0.35 E_{d y n}^{0.69},
$$

where $E_{\text {sta }}-$ static Young's modulus.

In the poroelastic method, $\varepsilon_{x}$ and $\varepsilon_{y}$ are generally used as the factors of calibration. First, the ratio of these factors is considered equal to 1 for the isotropic case. Then, this ratio changes to achieve the best adaptation to stress values obtained from direct testing, mechanism of failures in the wellbores or the pressure of drilling fluid. This model is used with no prior assumption about the state of stress. Then, the estimated horizontal stresses are calibrated and validated to achieve a model that is consistent with all the stress indicators.

Drilling operation disturbs the equilibrium condition of in situ stresses. Therefore, new (induced) stresses are provided around the wellbore. If the wellbores are affected by induced stresses, they have some failures. Thus, after the estimation of the principal stresses, they are converted into the induced stresses using existing relations. Stress concentration around a vertical wellbore, which has been drilled in parallel with the principal vertical stress and is in isotropic conditions in elastic environment, was described by Kirsch equations (Kirsch, 1898).

$$
\begin{aligned}
& \sigma_{r r}=\frac{1}{2}\left(\sigma_{H}+\sigma_{h}-2 P_{p}\right)\left(1-\frac{R^{2}}{r^{2}}\right)+ \\
& \frac{1}{2}\left(\sigma_{H}-\sigma_{h}\right)\left(1-4 \frac{R^{2}}{r^{2}}+3 \frac{R^{4}}{r^{4}}\right) \cos 2 \theta+\frac{\Delta P R^{2}}{r^{2}} ; \\
& \sigma_{\theta \theta}=\frac{1}{2}\left(\sigma_{H}+\sigma_{h}-2 P_{p}\right)\left(1+\frac{R^{2}}{r^{2}}\right)- \\
& \frac{1}{2}\left(\sigma_{H}-\sigma_{h}\right)\left(1+3 \frac{R^{2}}{r^{2}}\right) \cos 2 \theta-\frac{\Delta P R^{2}}{r^{2}} ; \\
& \sigma_{z z}=\sigma_{V}-2 v\left(\sigma_{H}-\sigma_{h}\right) \cos 2 \theta-P_{P},
\end{aligned}
$$

where $\theta$ - angle measured from the azimuth of $\sigma_{H}, \sigma_{\theta \theta}-$ effective tangential stress, $\sigma_{r r}$ - effective redial stress and $\sigma_{z z}-$ effective vertical stress.

Depending on the status of the three components of stresses, 6 modes of shear failure, and 3 modes of tensile failure may occur around the wellbore (Table 1) (Fjaer, Holt, Horsrud, Raaen, \& Risnes, 1992). Because of the the typical depth of oil reservoirs, the most common types of failure are of breakout and vertical tensile failure. The state of the induced stresses and failure mode that can be identified from image and caliper logs showed that the failures in this field, which are more observed in zones 3 , 4, 5 and 6, are mainly breakout (Figures 4 and 5).

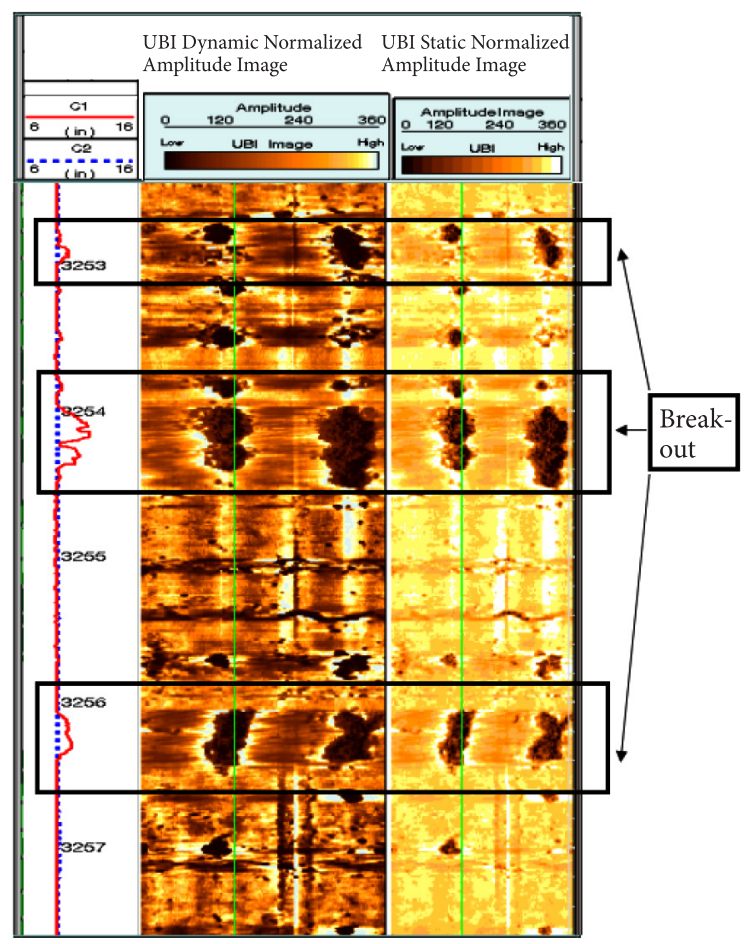

Figure 4. The image log shows breakouts in Ilam Formation 


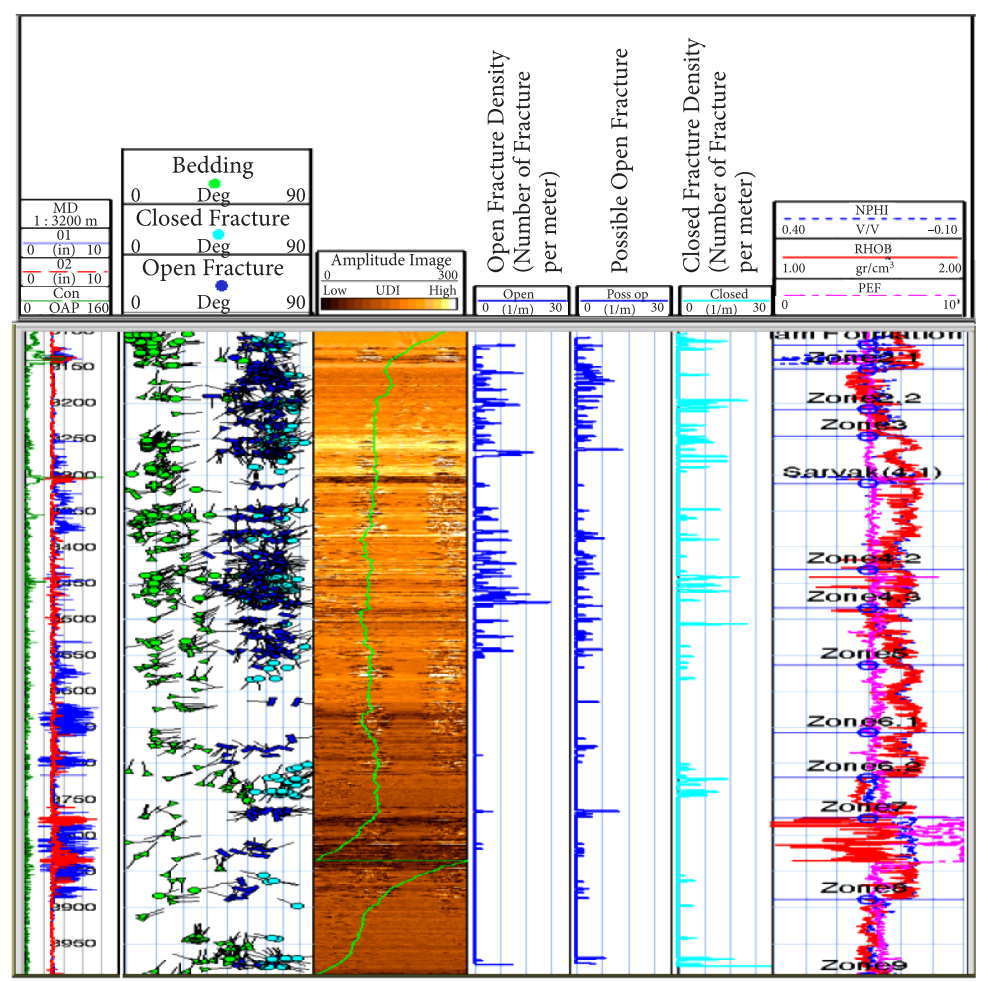

Figure 5. Composite plot of uranium corrected gamma ray (CGR), orthogonal caliper (C1 and C2), images, open and closed fracture, density (RHOB), notron (NPHI) and photoelectric factor (PEF) curves

Table 1. Multiple modes of wellbore failure

\begin{tabular}{|c|c|c|c|c|}
\hline \multicolumn{4}{|c|}{ Multiple modes of tensile failure } & Modes \\
\hline \multicolumn{3}{|c|}{$\sigma_{z z}=\sigma_{3}$} & $\begin{array}{l}\Delta=\sigma_{z z}-T>0 \\
P_{m}>-\left[\sigma_{V}+\sigma_{h}(2 v-3)+\right. \\
\left.\sigma_{H}(2 v-3)\right]\end{array}$ & $\begin{array}{l}\text { horizontal } \\
\text { (HOR) }\end{array}$ \\
\hline \multicolumn{3}{|c|}{$\sigma_{\theta \theta}=\sigma_{3}$} & $\begin{array}{l}\Delta=\sigma_{\theta \theta}-T>0 \\
P_{m}<3 \sigma_{h}-\sigma_{H}-P_{P}-T\end{array}$ & $\begin{array}{l}\text { Vertical } \\
\text { (VER): }\end{array}$ \\
\hline \multicolumn{3}{|c|}{$\sigma_{r r}=\sigma_{3}$} & $\begin{array}{l}\Delta=\sigma_{\mathrm{rr}}-T>0 \\
P_{m}>P_{P}+T\end{array}$ & $\begin{array}{l}\text { Cylinderical } \\
\text { (CYL) }\end{array}$ \\
\hline \multicolumn{5}{|c|}{ Multiple modes of compressive failure } \\
\hline$\sigma_{1}$ & $\sigma_{2}$ & $\sigma_{3}$ & \multicolumn{2}{|l|}{ Modes } \\
\hline$\sigma_{\theta \theta}$ & $\sigma_{z z}$ & $\sigma_{r r}$ & \multicolumn{2}{|c|}{ Wide breakout (WBO): Conventional breakout } \\
\hline$\sigma_{\theta \theta}$ & $\sigma_{r r}$ & $\sigma_{z z}$ & \multicolumn{2}{|c|}{$\begin{array}{l}\text { Low Angle Echelon (LAE): Requires high } \\
\text { mud weights. Failed rock will not fall into the } \\
\text { wellbore as } \sigma_{r r} \equiv \sigma_{2}\end{array}$} \\
\hline$\sigma_{z z}$ & $v_{r r}$ & $\sigma_{\theta \theta}$ & \multicolumn{2}{|c|}{$\begin{array}{l}\text { High Angle Echelon (HAE): Forms on } \\
\text { opposite side of well as a conventional breakout } \\
\text { but the failed rock will not fall into the } \\
\text { wellbore as } \sigma_{r r} \equiv \sigma_{2}\end{array}$} \\
\hline$\sigma_{z z}$ & $\sigma_{\theta \theta}$ & $\sigma_{r r}$ & \multicolumn{2}{|c|}{$\begin{array}{l}\text { Shallow Knockout (SKO): Results in failure all } \\
\text { the way around the wellbore }\end{array}$} \\
\hline$\sigma_{r r}$ & $\sigma_{z z}$ & $\sigma_{\theta \theta}$ & \multicolumn{2}{|c|}{$\begin{array}{l}\text { Narrow Breakout (NBO): Requires } \\
\text { unreasonably high mud weights. }\end{array}$} \\
\hline$\sigma_{r r}$ & $\sigma_{\theta \theta}$ & $\sigma_{z z}$ & \multicolumn{2}{|c|}{$\begin{array}{l}\text { Deep Knockout (SDKO): Requires } \\
\text { unreasonably high mud weights }\end{array}$} \\
\hline \multicolumn{5}{|c|}{$\begin{array}{l}\sigma_{1}, \sigma_{2} \text { and } \sigma_{3}: \text { maximum, mean and minimum stresses, } \sigma_{H} \\
\text { and } \sigma_{h}: \text { maximum and minimum horizontal stresses, } \theta \text { : Angle } \\
\text { measured from the azimuth of } \sigma_{H}, P_{P} \text { and } P_{m}: \text { Pore and } \\
\text { mud pressure, } \sigma_{\theta \theta}, \sigma_{r r} \text { and } \sigma_{z z} \text { : tangential, redial and vertical } \\
\text { effective stresses }\end{array}$} \\
\hline
\end{tabular}

\subsection{Direction of principal stresses}

There are several methods to identify direction of the principal stresses, such as orientation of breakouts and induced tensile fractures, orientation of hydraulic fractures and anisotropy of shear wave. Breakouts generally occur in the direction of minimum principal stress, in which the stress concentration has the highest value; while tensile fractures are formed in the direction of the maximum principal stress in which hoop stress is tensional. Thus in almost vertical wells, the wellbore breakout direction indicates the direction of the minimum horizontal stress and tensile fractures indicate the direction of the maximum horizontal stress. Direction of breakouts and induced tensile fractures can be identified using image logs or multiarm caliper data (Zoback, 2007).

In the studied field, the breakouts have mainly trending to NW-SE. So, directions of the maximum and minimum horizontal stresses are toward NE-SW and NW-SE (Figure 6).

\section{Results and discussions}

As was previously mentioned, the direct measurement tests are needed to verify the accuracy of the results of indirect methods. Unfortunately, few tests, however, have been conducted in the area and the only available datum is the results of an injection test, in which the minimum horizontal stress was determined to be $60 \mathrm{MPa}$ at a depth of $3450 \mathrm{~m}$ (Figure 7). The stress calculated using Zoback and Healy method is about $54 \mathrm{MPa}$ in the same depth. This approximate conformity, which can also see for the 

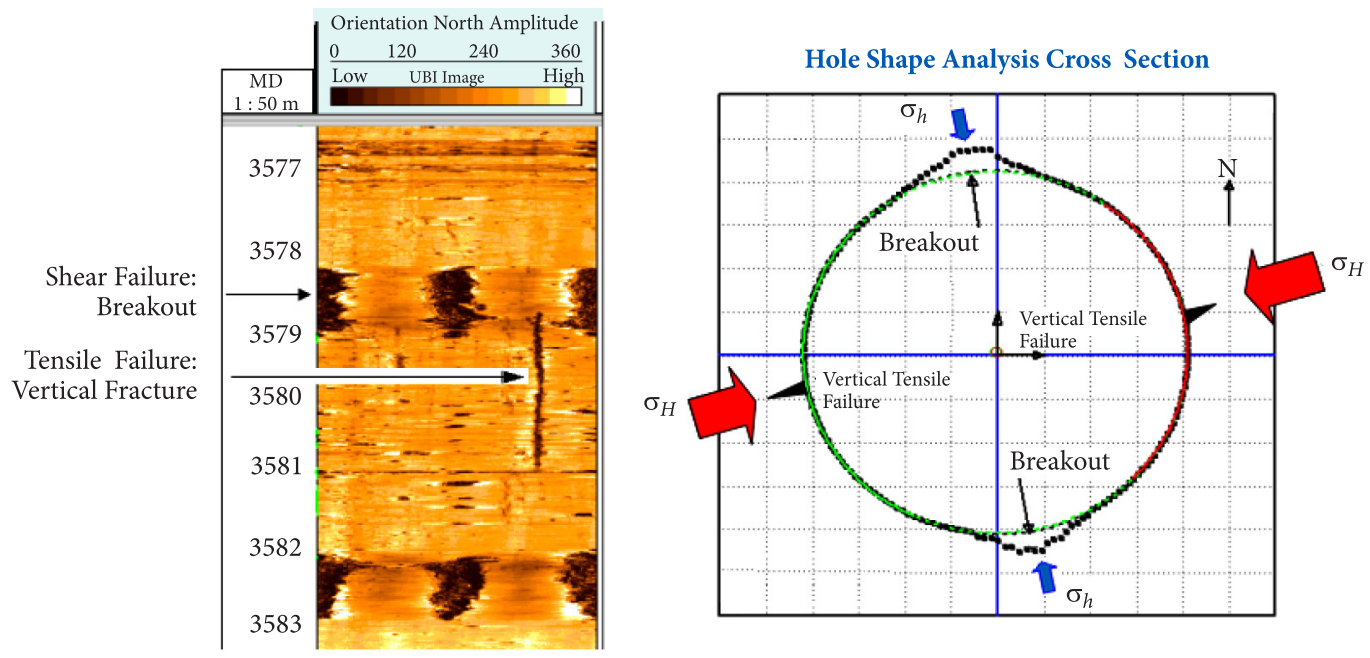

Figure 6. Tensile fracture and breakout are shown with respect to minimum and maximum horizontal stresses

a)

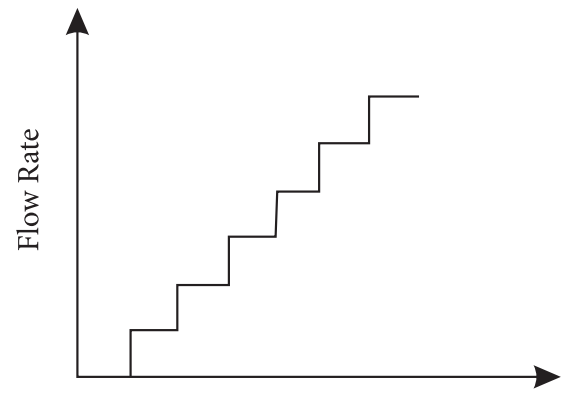

b)
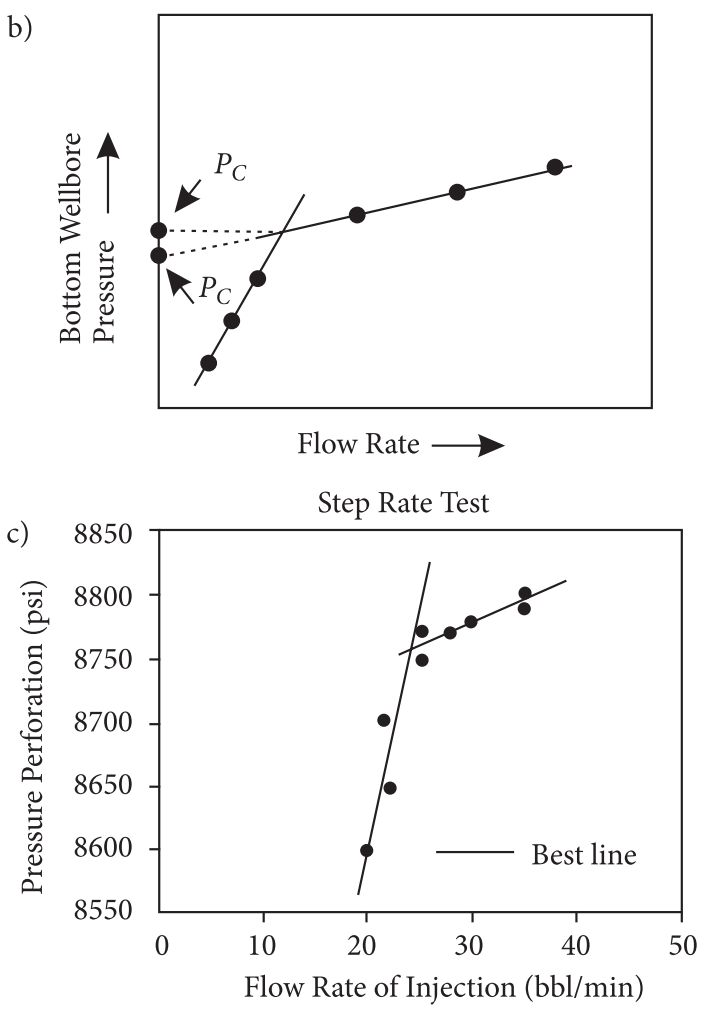

Figure 7. a) Curve line of injection flow rate based on time in a step rate test, b) Curve line of wellbores bottom pressure in each step based on step rate test, and c) Profile of step rate result in studied field results of poroelastic method, confirms that the stress regime is normal at this depth (Figures 8 and 9).

Other methods are presented for estimating the stress magnitude that are mainly laboratory work and calculate the stresses based on the propagation and width of breakouts. Barton et al. (1988) presented the following equation to calculate $\sigma_{\mathrm{H}}$ based on width of breakout.

$$
\begin{aligned}
\sigma_{H} & =\frac{U C S+2 P_{P}+\left(P_{m}-P_{P}\right)-\sigma_{h}\left(1+2 \cos 2 \theta_{b}\right)}{\left(1-2 \cos 2 \theta_{b}\right)} ; \\
2 \theta_{b} & =\pi-w_{B O} .
\end{aligned}
$$

This equation assumes that the width of breakout remains constant after the failure while its depth propagates. This increase depends on the magnitude of stress (Figure 10) (Haimson \& Herrick, 1985; Zoback, 2007). In addition, the stress concentration at the edge of the breakout is in equilibrium with the strength of the rock.

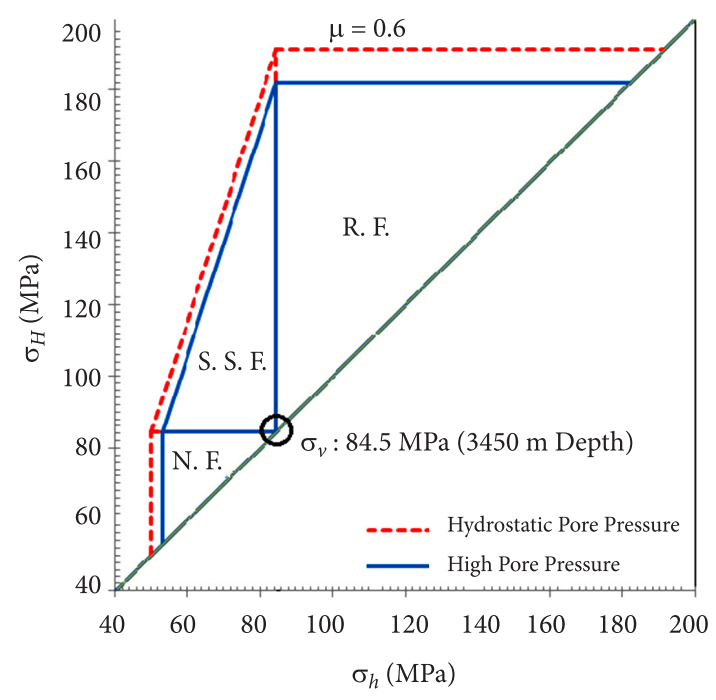

Figure 8. Polygons which define possible stress magnitudes are shown for a depth of $3450 \mathrm{~m}$ for a) hydrostatic pore pressure and b) high pore pressure 

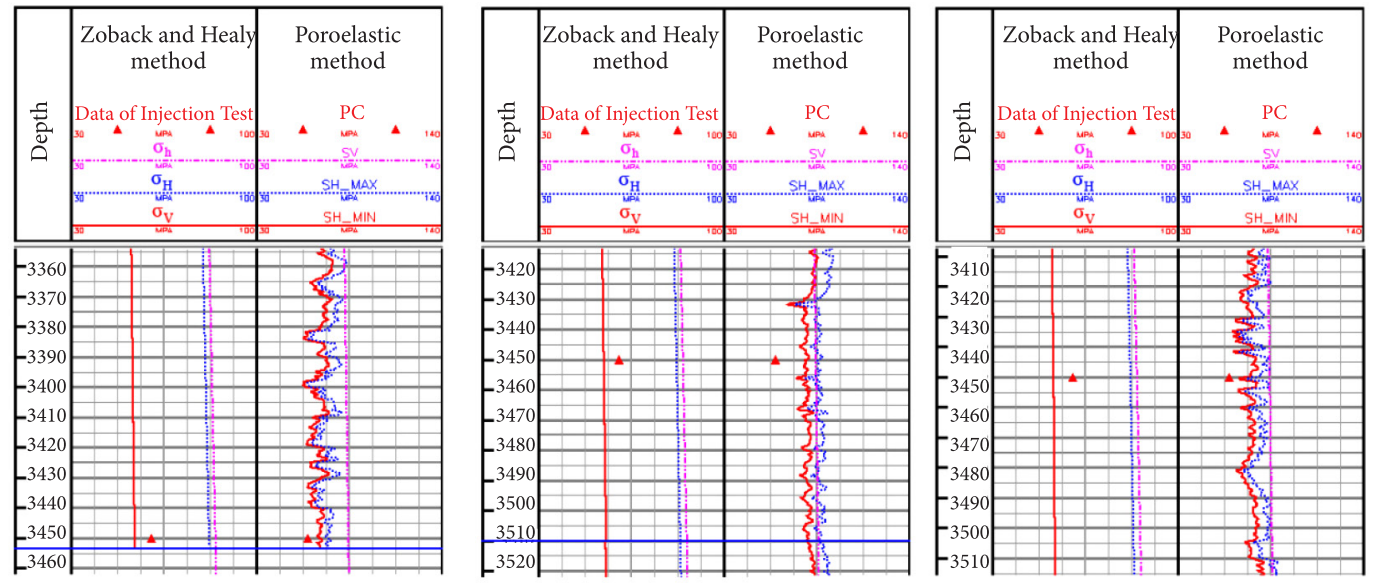

Figure 9. Comparison of log-derived stresses with data of injection test
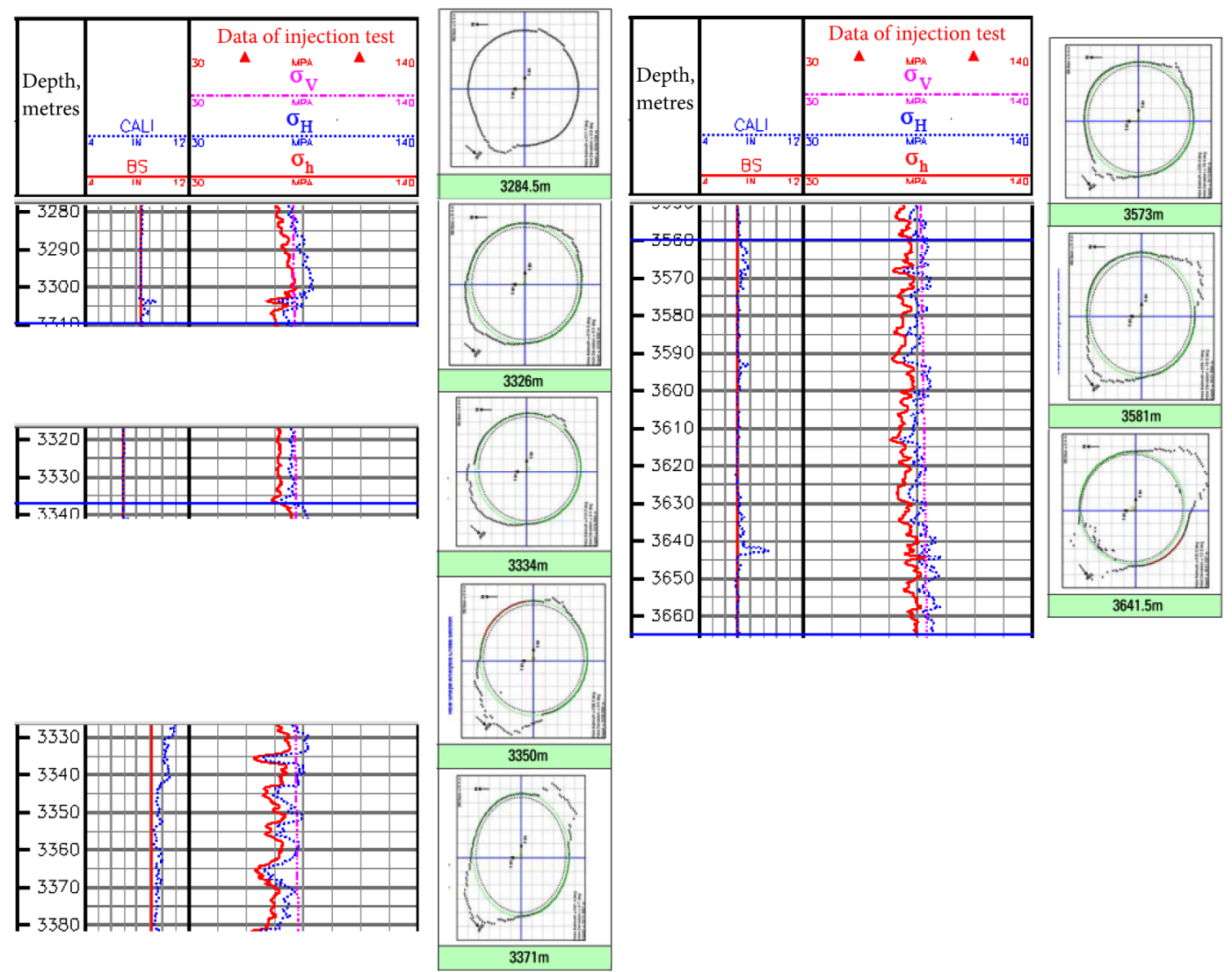

Figure 10. Comparison between depths of breakout with respect to stresses magnitude in some of intervals

Considering the fact that fracture systems and key seat are effective in creating the failure, some breakouts that occurred in the zones without these features were used in this method. The results are presented in Table 2. As can be seen in the table, the results of both methods show good conformity in some depth.

Another method to verify the accuracy of estimation is using different failure criteria such as the Mohr-Coulomb criterion. Based on failure criteria, the minimum stress needed to create failure in the wellbore can be estimated (Al-Ajmi, 2006). When a wellbore is drilled, a part of rocks is removed and the stress distribution around the wellbore will change. Therefore, the pressure of drilling fluid is used to balance again in the wellbore. If the pressure of fluid is not consistent with the in situ stresses of the formation, these stresses may cause failure of the rock. 
Table 2. Comparison of calculated $\sigma_{H}$ of two Poroelastic and Barton et al. (1998) methods

\begin{tabular}{|c|c|c|c|c|c|c|}
\hline $\begin{array}{c}\sigma_{h} \\
(\mathrm{MPa})\end{array}$ & $\begin{array}{c}\sigma_{H} \\
(\mathrm{MPa})\end{array}$ & $\begin{array}{c}P_{m} \\
(\mathrm{MPa})\end{array}$ & $\begin{array}{c}P_{p} \\
(\mathrm{MPa})\end{array}$ & $\begin{array}{c}\mathrm{UCS} \\
(\mathrm{MPa})\end{array}$ & $\begin{array}{c}W_{B O} \\
(\text { actual })\end{array}$ & $\begin{array}{c}W_{B O} \\
\text { (estimated) } \\
\text { Barton } \\
\text { Methode }\end{array}$ \\
\hline 84.74 & 99.40 & 41.93 & 46.61 & 102.75 & 80 & 73.11 \\
\hline 84.54 & 99.18 & 41.93 & 46.62 & 102.44 & 82 & 72.84 \\
\hline 83.82 & 97.53 & 43.14 & 46.91 & 96.34 & 75 & 76.73 \\
\hline 84.11 & 98.02 & 43.15 & 46.92 & 97.79 & 74 & 75.39 \\
\hline 83.80 & 98.44 & 41.34 & 42.11 & 109.53 & 59 & 65.53 \\
\hline 83.18 & 97.51 & 41.34 & 42.11 & 110.35 & 60 & 59.65 \\
\hline 76.20 & 87.93 & 42.77 & 43.38 & 88.15 & 56 & 61.27 \\
\hline 76.80 & 88.85 & 42.77 & 43.38 & 90.60 & 56 & 59.43 \\
\hline 80.39 & 94.00 & 43.01 & 46.08 & 97.15 & 64 & 61.12 \\
\hline 80.74 & 94.54 & 43.01 & 46.08 & 98.61 & 62 & 60.16 \\
\hline 80.97 & 93.91 & 42.00 & 48.28 & 97.02 & 60 & 58.14 \\
\hline 80.94 & 93.84 & 42.00 & 48.28 & 93.70 & 61 & 66.14 \\
\hline 81.34 & 94.45 & 42.06 & 48.39 & 96.57 & 64 & 61.56 \\
\hline 83.70 & 97.12 & 43.38 & 49.20 & 93.09 & 75 & 76.92 \\
\hline 84.86 & 98.64 & 43.39 & 49.20 & 96.17 & 77 & 76.29 \\
\hline 89.68 & 104.07 & 48.44 & 51.38 & 108.31 & 58 & 56.82 \\
\hline 89.06 & 103.15 & 48.44 & 51.39 & 106.19 & 57 & 57.48 \\
\hline 79.82 & 92.77 & 40.06 & 40.42 & 103.82 & 60 & 60.03 \\
\hline 79.96 & 93.00 & 40.06 & 40.42 & 106.91 & 58 & 53.12 \\
\hline 80.60 & 93.90 & 40.14 & 40.51 & 103.36 & 63 & 66.09 \\
\hline 80.19 & 93.24 & 40.14 & 40.51 & 102.16 & 64 & 65.98 \\
\hline 83.18 & 97.18 & 40.54 & 40.92 & 103.06 & 81 & 78.83 \\
\hline 80.86 & 93.78 & 40.54 & 40.93 & 97.010 & 80 & 78.82 \\
\hline
\end{tabular}

The calculated stress values should be modified, if a failure is to be created in the wellbore at some depth on the basis of the selected criteria, but no failure can be seen in image logs at same depth. Depending on the type of failure observed in the image logs, the following relations must be established to create breakout (Fjaer et al., 2008):

$$
\begin{aligned}
& \sigma_{\theta \theta \max }=\sigma_{1}=3 \sigma_{H}-\sigma_{h}-P_{W}-P_{p} ; \\
& \sigma_{r r}=\sigma_{3}=P_{W}-P_{p} ; \\
& \sigma_{1} \leq U C S+\sigma_{3} \tan ^{2}\left(45-\frac{\varphi}{2}\right) ; \\
& P_{m} \leq P_{B O}=\frac{1}{1+\tan ^{2}\left(45-\frac{\varphi}{2}\right)} \times \\
& {\left[3 \sigma_{H}-\sigma_{h}-P_{p}-U C S+P_{P} \tan ^{2}\left(45-\frac{\varphi}{2}\right)\right] \leq 0 .}
\end{aligned}
$$

Equation 16 is the Mohr-Coulomb criterion. If another criterion is intended, the equation will change. Equation 16 is used to calculate the minimum mud pressure required to protect wellbores of failure and instability based on Mohr-Coulomb criterion. By applying the Mohr-Coulomb failure criterion, the upper limit of the mud pressure was calculated to prevent the vertical tensile failure.

$P_{m} \geq$

$$
\frac{U C S-P_{P}\left[\tan ^{2}\left(45-\frac{\varphi}{2}\right)-1\right]-\sigma_{V}+2 \nu\left(\sigma_{H}-\sigma_{h}\right)+3 \sigma_{h}-\sigma_{H}}{\tan ^{2}\left(45-\frac{\varphi}{2}\right)} .
$$

Anemangely et al. (2018a) provided the following equation for calculating the $\varphi$ parameter:

$$
\begin{aligned}
& \varphi=26 / 5-37 / 4\left(1-N P H I-V_{\text {shale }}\right)+ \\
& 62 / 1\left(1-N P H I-V_{\text {shale }}\right)^{2} ; \\
& V_{\text {shale }}=\frac{C G R-C G R_{\min }}{C G R_{\max }-C G R_{\min }} .
\end{aligned}
$$

Safe mud window for drilling is determined based on the maximum and minimum allowable mud pressure (Figure 11).

In these equations, uniaxial compressive strength (UCS) and the angle of internal friction $(\varphi)$ are required; and the following equations were used to calculate them
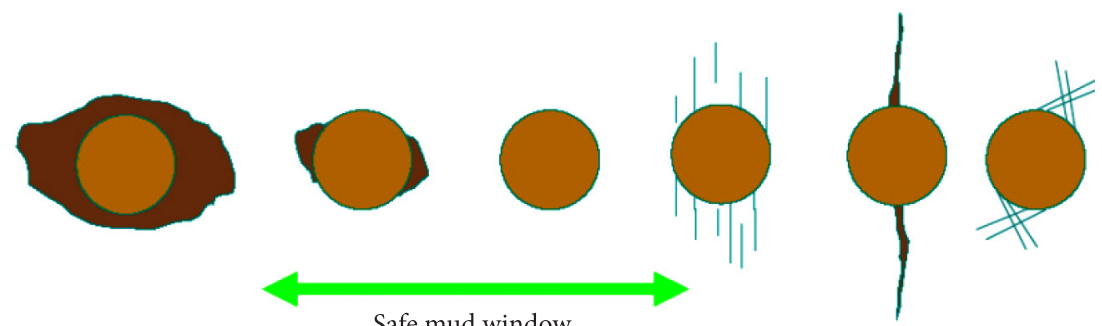

Safe mud window

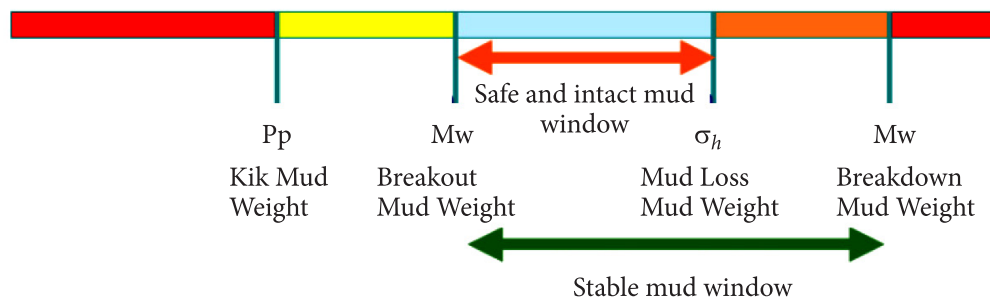

Figure 11. Safe mud weight window 

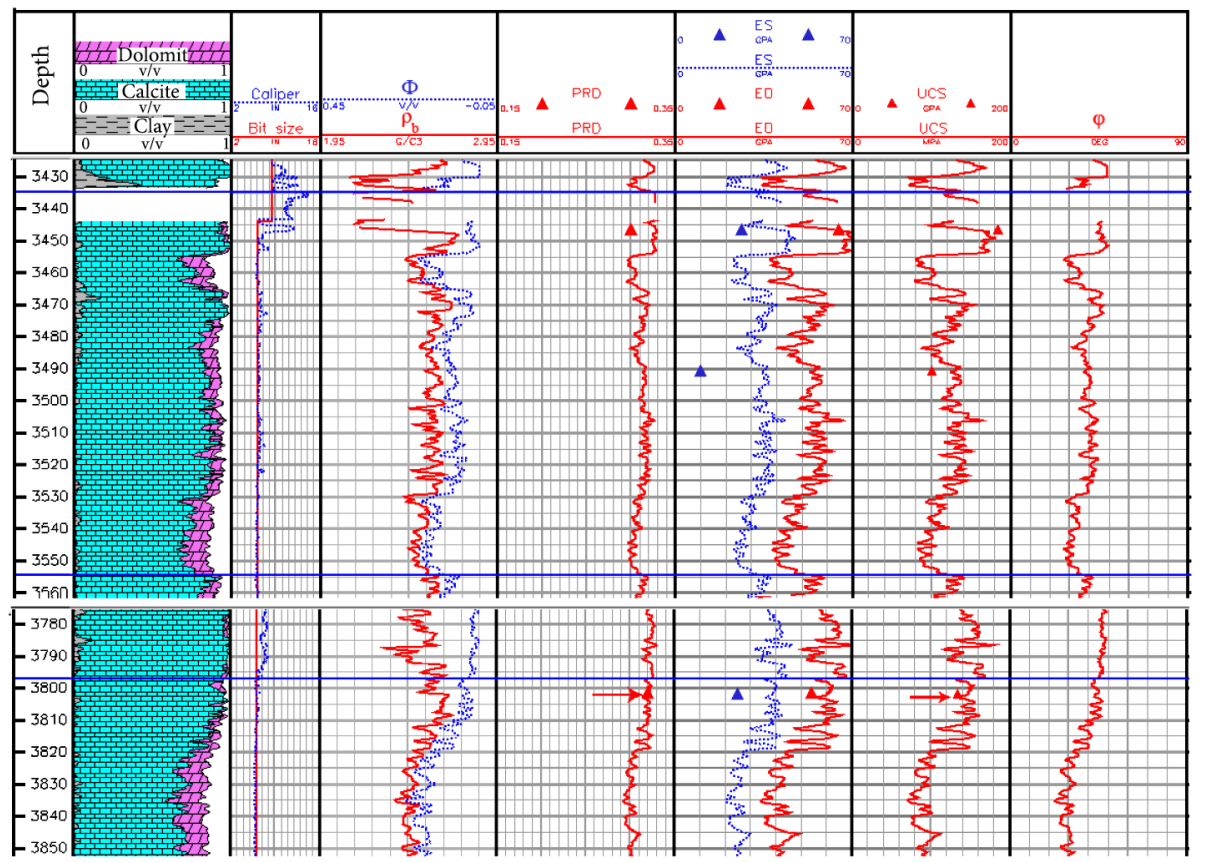

Figure 12. Lithology, Bit Size, caliper, porosity $(\Phi)$, density $(\rho \mathrm{b})$, elastic constants (E and $v)$, rock Strength (UCS) and internal friction angle $(\phi)$ from logs that calibrated to core

(Zoback, 2007; Ameen, Smart, Somerville, Hammilton, \& Naji, 2009; Anemangely et al., 2018a). The results show good conformity with laboratorial data (Figure 12).

$$
\begin{aligned}
& U C S=135.9 \operatorname{EXP}(-4.8 \Phi) ; \\
& \varphi=49.03-1.26 \Phi,
\end{aligned}
$$

where $\Phi$ : Porosity

$$
\mathrm{UCS}=2.27 \text { Esta }+4.74
$$

According to the predicted safe mud window, real mud pressure is less than the minimum allowable mud pressure in some depth. This pressure can cause instability and breakout of wellbore. Results of the equation 16 showed that there is good compliance between predicted and actual locations of failures (Figure 13). However, a few differences can be seen between two values (Figure 14). Several reasons can be cited for this difference. It may be due to incorrect estimation of geomechanical parameters (uniaxial compressive strength, angle of internal friction and elastic constants), magnitude of stresses (horizontal stresses and pore pressure), Biot's constant and/or tectonic anisotropy ratio.

Fracture systems decrease the strength of rock mass and internal friction angle. If the fractures planes cut across the wellbore trajectory, they may lead to failure which depends on the density, direction and dip of fractures with respect to azimuth and deviation of wellbore. Its effect can be clearly seen in the zones that have fractures. The Sarvak Formation, in which the failures observed have mainly taken place, has two fracture sets (Figure 5). Another phenomenon that can be used as evidence on the impact of the fractures in creating failure is the asymmetry in the shape and width of breakouts between two walls opposite each other, which can be caused by the strength anisotropy (Figure 15) (Zoback, 2007).

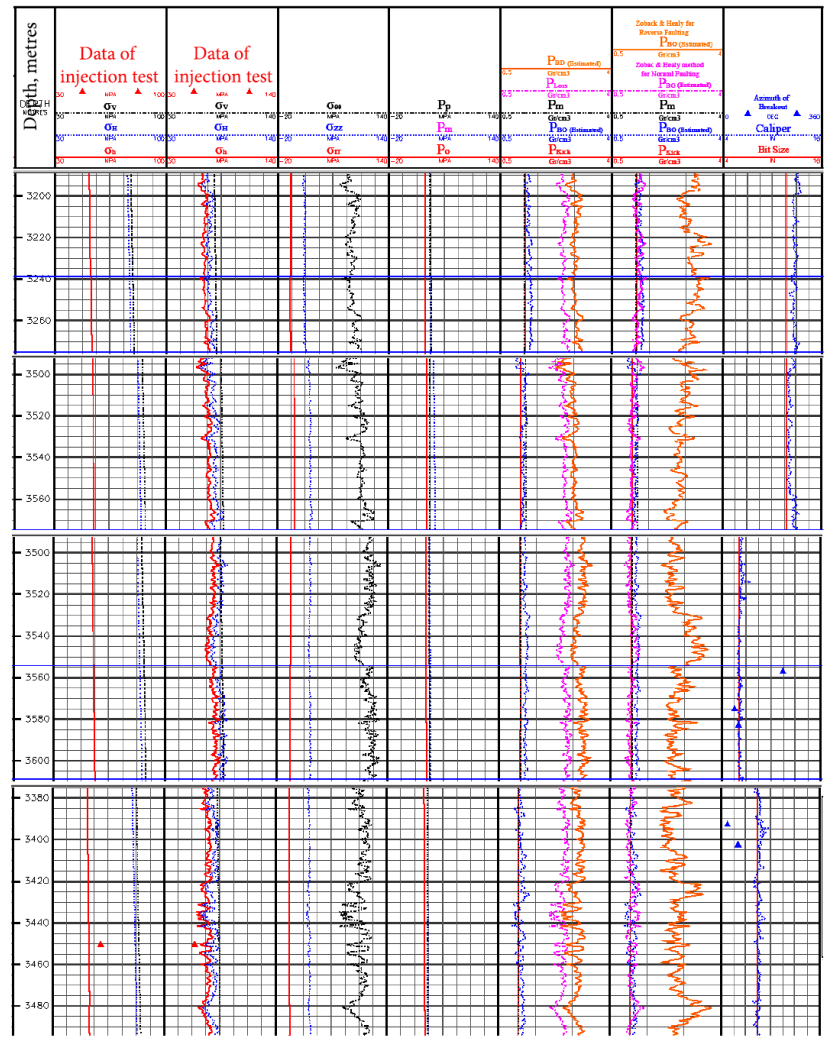

Figure 13. Variation of mud presure, pore presure and stress magnitudes with respect to depth for two Zoback and Healy (1984) and poroelastic methods 


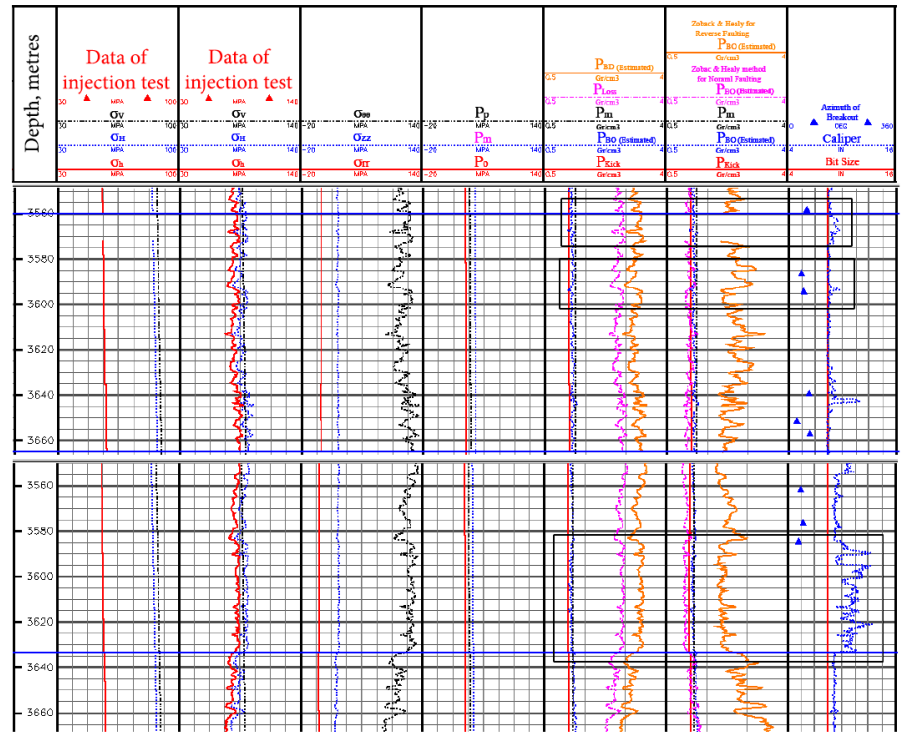

Figure 14. Mud weight window shows that the wellbore should be stable and without failure while caliper log shows the failure in the same depth

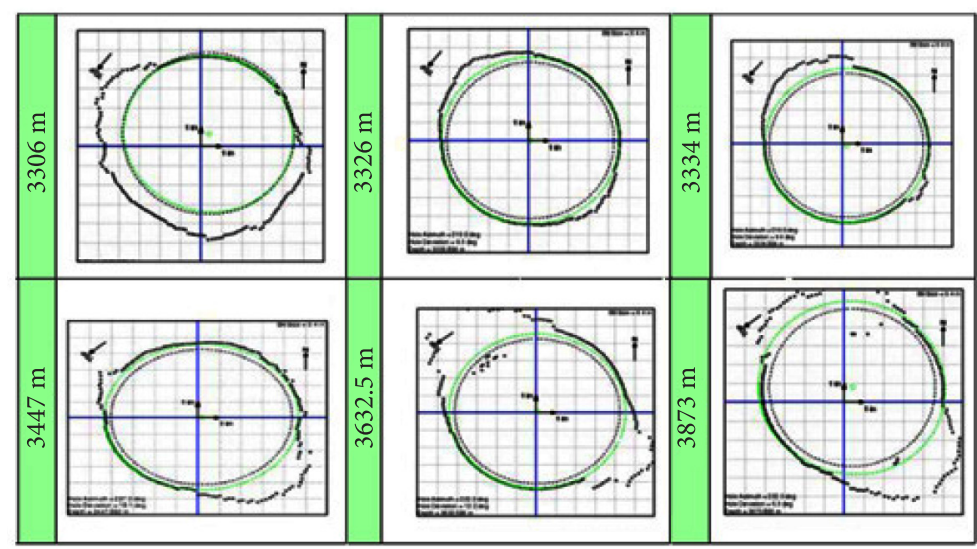

Figure 15. Image of breakouts influenced by rock strength anisotropy associated with the presence of fracture planes cutting across a wellbore

A collision between drill string and the wellbores locally increases the stress, which certainly will have a considerable effect on the creation of a failure. The impact of collision on the wellbore, which is known as key seat, is detectable by image logs multi-arm caliper (Figures 4 and 16).

Another effective factor in creation of failure is surge and swab pressures: the latter is caused due to movement of drill string in upward and consequently downfall of the pressure on the wellbore bottom. Swab pressure is the opposite of this case. The surge and swab pressures are likely to cause induced tensile fractures and shear fracture, respectively.

As was previously mentioned, there is no fault in studied field that has folding with very gentle dip. Therefore, stress regime is less likely to be reverse in this field. Furthermore, in case there is a reverse stress regime, a high mud pressure is needed to control the failure in the wellbores, while the pressure of drilling fluid is almost equal to the pore pressure, which is not sufficient to control the very high stress in reverse mode.

However, the minimum pressure of drilling fluid to prevent failure in reverse stress mode was calculated on the basis of equation 17 using the stresses calculated by the Zoback and Healy method for reverse state (Figure 13). As there is considerable difference between actual and calculated values, a failure should occur in the wellbores, but this is not the case in reality and the wellbore is stable. Thus, the possibility of reverse stress regime in this field is rejected. The mud pressure required to control failure in the normal state is closer to the actual pressure (Figure 12).

Considering the evidence available, the estimated stresses can be reliably used to analyze the stability of the wellbores. As can be seen in Figures 13 and 14, in the studied field, the stress mode is mainly normal and strikeslip in a few intervals. Under these stresses, the wellbores are mostly stable and the failures usually occur in small and finite dimensions. 


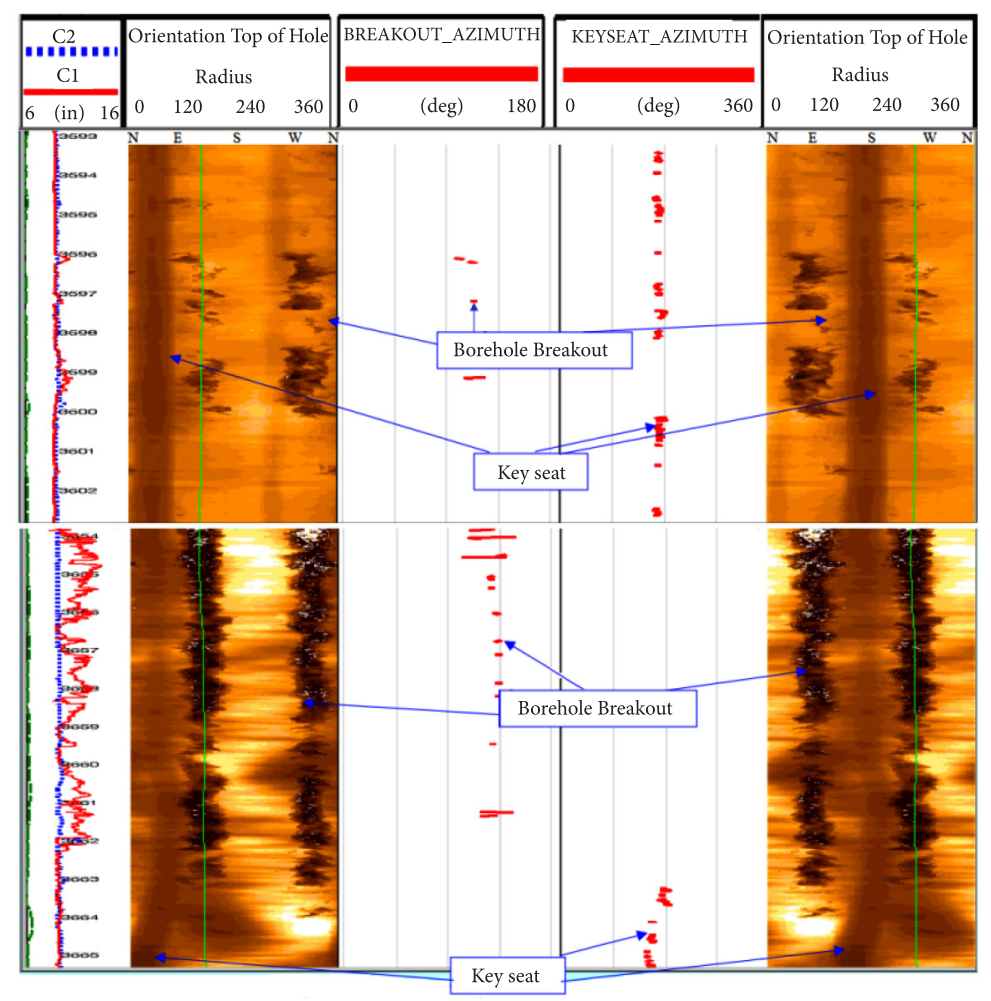

Figure 16. Images showing key seat (on the low side of the wellbore) in a section of Sarvak Formation. The first image (shown on the left) is oriented from North and the second image (on the right) is oriented with respect to Top of Hole, which means top of hole is on the edges and bottom / low side of the wellbore is in the middle of the image

\subsection{Estimated stress field by the neural network}

Neural networks are widely used in different areas of research for mainly different tasks of prediction or classification on a broad range of statistically different datasets. Hence, it looked obvious to try them on these types of data as well. We used different architectures of fully connected neural network in order to reach a reliable system for predicting one sample outputs based only on that sample inputs.

In the field of artificial neural network application in the oil industry, Anemangely, Ramezanzadeh, Tokhmechi, Molaghab, and Mohammadian (2018b) and Anemangely, Ramezanzadeh, and Tokhmechi (2017), used artificial neural network capabilities to estimate the penetration rate in well drilling as well as estimate the travel time of shear wave in the rock. They used petrophysical and mud logging data for the training and estimation of artificial neural network and obtained acceptable results (Anemangely et al., 2017, 2018b).

A neural network is a connectionist model that in general consists of a series of layers connected to each other. Each layer can have an optional amount of nodes and the way these nodes in each layer connect to the nodes in an adjacent layer makes different architectures of neural networks. In a fully connected neural network, all of the nodes of each layer is fully connected to the next layer. Each input is considered a node in the input layer and the same goes for the outputs in the output layer. A hidden layer is any layer that comes between the input and output layer. The following formula describes how we can reach to the hidden layers outputs:

$$
y_{h}=a\left(W_{1} x+b_{1}\right),
$$

where $W$ is the weights matrix transforming the inputs vector $x$ and $b$ is a bias vector to avoid the transformed vector passing through the origin point at all times. is an activation function which basically can be any non-linear function but the famous choices that work well in different practical scenarios are sigmoid, hyperbolic tangent and rectified linear units (ReLU) functions. The ReLU function that we used here is a function that turns the negative values to zero and keeps the positive values as themselves. Use of a non-linearity can help a lot in different pragmatic situations since our problems cannot usually be solved with a simple linear model. The output layer can be reached by applying a similar formula but this time the inputs are the outputs of the hidden layers and here we did not use any activation function for this layer. Thus, we can write:

$$
y_{\text {out }}=W_{2} y_{h}+b_{2} \text {. }
$$

The weights matrix, bias vectors and the hidden nodes are trainable variables, which means that through training them we ensure an output similar to the target output that was to be predicted. The training methods can vary from one task to another but the most used training process is called stochastic gradient descent algorithm. Another 
method that has gained a lot of popularity over the last few years is the Adam optimizer, which considers different learning rates for different variables in contrast to the gradient descent that only uses one single learning rate through the training phase. Here we use only Adam for faster and better convergence to the targets. The cost function, with which we optimized the trainable variables, was mean square error (MSE) which is defined in this manner:

$$
M S E=\frac{1}{n} \sum_{i=1}^{n}\left(Y_{i}-\widehat{Y_{i}}\right)^{2},
$$

where $Y_{i}$ is the predicted output, $\widehat{Y}_{i}$ is the target (real) output and $n$ is the number of samples.

\subsubsection{Experiments and results}

All of the experiments were done using Tensorflow with python programming language. All of the data were shuffled randomly to avoid the possible dependency of different samples on each other. We also scaled each variable by the maximum number of that variable type (each variable divided by the maximum of that variable type) (Anemangely et al., 2018b). For the figures, we scaled them back to reach a realistic evaluation. Scaling or normalization plays an important role in training neural network. Here we preferred scaling to normalization because for this task it reached a better result and a faster convergence. The overall MSE is the mean value of all the scaled MSEs for each output. We used 3120 samples for training set and 165 for testing set. We divided data into different batches for training to investigate the best batch size for training the best model. A validation set was used for early stopping of the training procedure. We used the last batch of training data for validation set and we did not use that last batch to train any parameters. An early stop for training was used to avoid overfitting the model on the training set. We also tried using dropouts. Dropouts are layers that randomly destroy a percentage of the connections between two layers. Use of dropouts for a more robust system especially when we have noisy data usually gives better results. Here we use the term "Keep drop out" to refer to the percentage of connections that we keep. For example, by $100 \%$ keep drop out, we mean that all the nodes in one layer are fully connected to the nodes of the next layer. We initialized all the weights by a normal distribution with the mean of zero and standard deviation of 0.1 . Biases were initialized in the same manner but instead of zero mean, we gave them 0.1 mean.

First, we investigated different hidden layers and nodes and as apparent from the table, the system with 1 hidden layer and 1024 hidden nodes gave the best overall MSE. Only three of the best results are shown in Table 3. The number of nodes and hidden layers were chosen heuristically. The best result was for using only one hidden layer with 1024 nodes. We did investigate putting more layers with 1024 nodes or one hidden layer with 512 but those did not perform as well as the one hidden layer with 1024 nodes. The reason may be the fact that 1024 nodes can be enough for our data and using more layers would overcomplicate the problem in a way that the model could not represent the outputs predictions well enough.

Then we wanted to see the effect of changing the batch size. We experimented with 10, 20 and 100 as the size of batches for training. From Table 4, we can see that using batch size as 20 yields the best results.

After that, we tried using dropouts. As one can see in Table 5, using dropouts yielded worse overall MSE, which

Table 3. Different hidden layers comparison

\begin{tabular}{|c|c|c|c|c|c|c|}
\hline $\begin{array}{c}\text { Number of } \\
\text { hidden layers }\end{array}$ & $\begin{array}{c}\text { Hidden layer } \\
\text { nodes }\end{array}$ & Batch Size & Keep drop out & $\begin{array}{c}\text { Activation } \\
\text { Function }\end{array}$ & Learning Rate & Overall MSE \\
\hline 1 & 1024 & 100 & $100 \%$ & ReLU & 0.0001 & $2.37 \mathrm{e}-5$ \\
\hline 2 & 512,256 & 100 & $100 \%$ & ReLU & 0.0001 & $2.48 \mathrm{e}-5$ \\
\hline 3 & $512,256,128$ & 100 & $100 \%$ & ReLU & 0.0001 & $4.13 \mathrm{e}-5$ \\
\hline
\end{tabular}

Table 4. Different batch size comparison

\begin{tabular}{|c|c|c|c|c|c|c|}
\hline $\begin{array}{c}\text { Number of } \\
\text { hidden layers }\end{array}$ & $\begin{array}{c}\text { Hidden layer } \\
\text { nodes }\end{array}$ & Batch Size & Keep drop out & $\begin{array}{c}\text { Activation } \\
\text { Function }\end{array}$ & Learning Rate & Overall MSE \\
\hline 1 & 1024 & 100 & $100 \%$ & ReLU & 0.0001 & $2.37 \mathrm{e}-5$ \\
\hline 1 & 1024 & 20 & $100 \%$ & ReLU & 0.0001 & $1.99 \mathrm{e}-5$ \\
\hline 1 & 1024 & 10 & $100 \%$ & ReLU & 0.0001 & $4.61 \mathrm{e}-5$ \\
\hline
\end{tabular}

Table 5. Use of dropouts for prediction

\begin{tabular}{|c|c|c|c|c|c|c|}
\hline $\begin{array}{c}\text { Number of } \\
\text { hidden layers }\end{array}$ & $\begin{array}{c}\text { Hidden layer } \\
\text { nodes }\end{array}$ & Batch Size & Keep drop out & $\begin{array}{c}\text { Activation } \\
\text { Function }\end{array}$ & Learning Rate & Overall MSE \\
\hline 1 & 1024 & 20 & $100 \%$ & ReLU & 0.0001 & $1.99 \mathrm{e}-5$ \\
\hline 1 & 1024 & 20 & $90 \%$ & ReLU & 0.0001 & $4.22 \mathrm{e}-5$ \\
\hline 1 & 1024 & 20 & $80 \%$ & ReLU & 0.0001 & $1.96 \mathrm{e}-4$ \\
\hline
\end{tabular}


means that our data was clean enough and the training set can easily represent the test set as well. Dropouts here used only between the hidden layer and output layer.

We also investigated using a hyperbolic tangent instead of ReLU. The recent trends in neural networks show an interest towards using ReLU activation function instead of a hyperbolic tangent (Table 6). In this work, ReLU did give a better performance and a faster convergence.

In the end, we tried different initial learning rates. Learning rate of 0.00001 was found to be the best in this situation (Table 7).

All of the Figures 2-10 are for the case of one hidden layer with 1024 nodes, bath size of 20, no dropout layer, activation function of ReLU and learning rate of 0.00001 . The MSEs in figures are also represented in Table 8. Theses MSEs are for each class and they are not scaled.

Figure 17 estimates elastic rock properties associated with the estimation error is shown.

Figure 18 also shows the stress field estimated by the artificial neural network.

The precision of the MSE parameter for each estimate indicates that the artificial neural network has a large potential for estimating and calculating these challenging parameters at deep underground.

After reaching a good prediction system, we wanted to analyze the effect of each feature on the prediction of each class. For this purpose, we considered a simple formula of in which $x$ and $y$ are respectively the input features and the output class, which is only one single number, and $b$ is the bias vector and $w$ is the weight vector. Then we trained the $\mathrm{w}$ and $\mathrm{b}$ with Adam optimizer. With a trained weight vector, we can tell how effective is each of the elements of the $\mathrm{x}$ vector based on the corresponding element in the weight vector since we are multiplying them to produce the output. Because the value of each element in the weight vector is important not the sign of it, we got the absolute value of each element and then divided them by the sum of all the elements to reach a percentage representation of the effectiveness of each input feature.

In Table 9, the weight of each of the input parameters of the model is shown in the estimation of the output parameters. Obviously, depending on the nature of the output parameter, the effect of each of the input parameters will vary. For example, according to Table 9, in the

Table 6. Different activation functions comparison

\begin{tabular}{|c|c|c|c|c|c|c|}
\hline $\begin{array}{c}\text { Number of } \\
\text { hidden layers }\end{array}$ & $\begin{array}{c}\text { Hidden layer } \\
\text { nodes }\end{array}$ & Batch Size & Keep drop out & $\begin{array}{c}\text { Activation } \\
\text { Function }\end{array}$ & Learning Rate & Overall MSE \\
\hline 1 & 1024 & 20 & $100 \%$ & ReLU & 0.0001 & $1.99 \mathrm{e}-5$ \\
\hline 1 & 1024 & 20 & $100 \%$ & Tanh & 0.0001 & $3.95 \mathrm{e}-5$ \\
\hline
\end{tabular}

Table 7. Different learning rate comparison

\begin{tabular}{|c|c|c|c|c|c|c|}
\hline $\begin{array}{c}\text { Number of } \\
\text { hidden layers }\end{array}$ & $\begin{array}{c}\text { Hidden layer } \\
\text { nodes }\end{array}$ & Batch Size & Keep drop out & $\begin{array}{c}\text { Activation } \\
\text { Function }\end{array}$ & Learning Rate & Overall MSE \\
\hline 1 & 1024 & 20 & $100 \%$ & ReLU & 0.001 & $1.30 \mathrm{e}-4$ \\
\hline 1 & 1024 & 20 & $100 \%$ & ReLU & 0.0001 & $1.99 \mathrm{e}-5$ \\
\hline 1 & 1024 & 20 & $100 \%$ & ReLU & 0.00001 & $9.57 \mathrm{e}-6$ \\
\hline
\end{tabular}

Table 8. Prediction of each class in mean square error

\begin{tabular}{|c|c|c|c|c|c|c|c|c|}
\hline Gs(GPA) & Kd(GPA) & Ed(GPA) & Es(GPA) & V & UCS(MPA) & Sv(MPA) & SH(MPA) & Sh(MPA) \\
\hline $5.20 \mathrm{e}-4$ & $1.12 \mathrm{e}-3$ & $1.83 \mathrm{e}-2$ & $1.76 \mathrm{e}-3$ & $3.77 \mathrm{e}-6$ & $1.12 \mathrm{e}-1$ & $3.23 \mathrm{e}-2$ & $4.80 \mathrm{e}-2$ & $6.17 \mathrm{e}-2$ \\
\hline
\end{tabular}

Table 9. Effect of each feature on the prediction of each class

\begin{tabular}{|c|c|c|c|c|c|c|c|c|c|c|}
\hline & Depth & GR & RHOB & NPHI & DTco & DTsm & BS & HD Min & HD Max & PP \\
\hline Gs & $11.21 \%$ & $0.34 \%$ & $30.34 \%$ & $12.52 \%$ & $12.44 \%$ & $22.73 \%$ & $4.21 \%$ & $5.36 \%$ & $0.26 \%$ & $0.60 \%$ \\
\hline Kd & $9.27 \%$ & $0.44 \%$ & $21.62 \%$ & $25.34 \%$ & $13.26 \%$ & $13.39 \%$ & $7.53 \%$ & $5.27 \%$ & $0.50 \%$ & $3.39 \%$ \\
\hline Ed & $6.91 \%$ & $0.22 \%$ & $34.32 \%$ & $14.12 \%$ & $17.70 \%$ & $16.33 \%$ & $6.04 \%$ & $2.01 \%$ & $1.89 \%$ & $0.46 \%$ \\
\hline Es & $9.07 \%$ & $0.50 \%$ & $18.67 \%$ & $30.52 \%$ & $10.90 \%$ & $12.77 \%$ & $8.56 \%$ & $3.95 \%$ & $0.13 \%$ & $4.92 \%$ \\
\hline V & $19.37 \%$ & $0.35 \%$ & $7.41 \%$ & $0.90 \%$ & $28.10 \%$ & $22.64 \%$ & $1.40 \%$ & $5.47 \%$ & $5.20 \%$ & $9.16 \%$ \\
\hline UCS & $11.52 \%$ & $0.25 \%$ & $12.52 \%$ & $63.04 \%$ & $0.07 \%$ & $2.73 \%$ & $0.21 \%$ & $3.58 \%$ & $4.56 \%$ & $1.51 \%$ \\
\hline Sv & $49.07 \%$ & $0.48 \%$ & $7.57 \%$ & $3.83 \%$ & $10.65 \%$ & $4.71 \%$ & $0.88 \%$ & $0.41 \%$ & $1.50 \%$ & $21.32 \%$ \\
\hline SH & $18.31 \%$ & $0.23 \%$ & $6.00 \%$ & $1.56 \%$ & $34.76 \%$ & $17.83 \%$ & $0.40 \%$ & $1.67 \%$ & $2.25 \%$ & $16.99 \%$ \\
\hline Sh & $14.86 \%$ & $0.46 \%$ & $5.94 \%$ & $6.50 \%$ & $23.52 \%$ & $16.29 \%$ & $0.52 \%$ & $1.88 \%$ & $3.76 \%$ & $26.27 \%$ \\
\hline
\end{tabular}



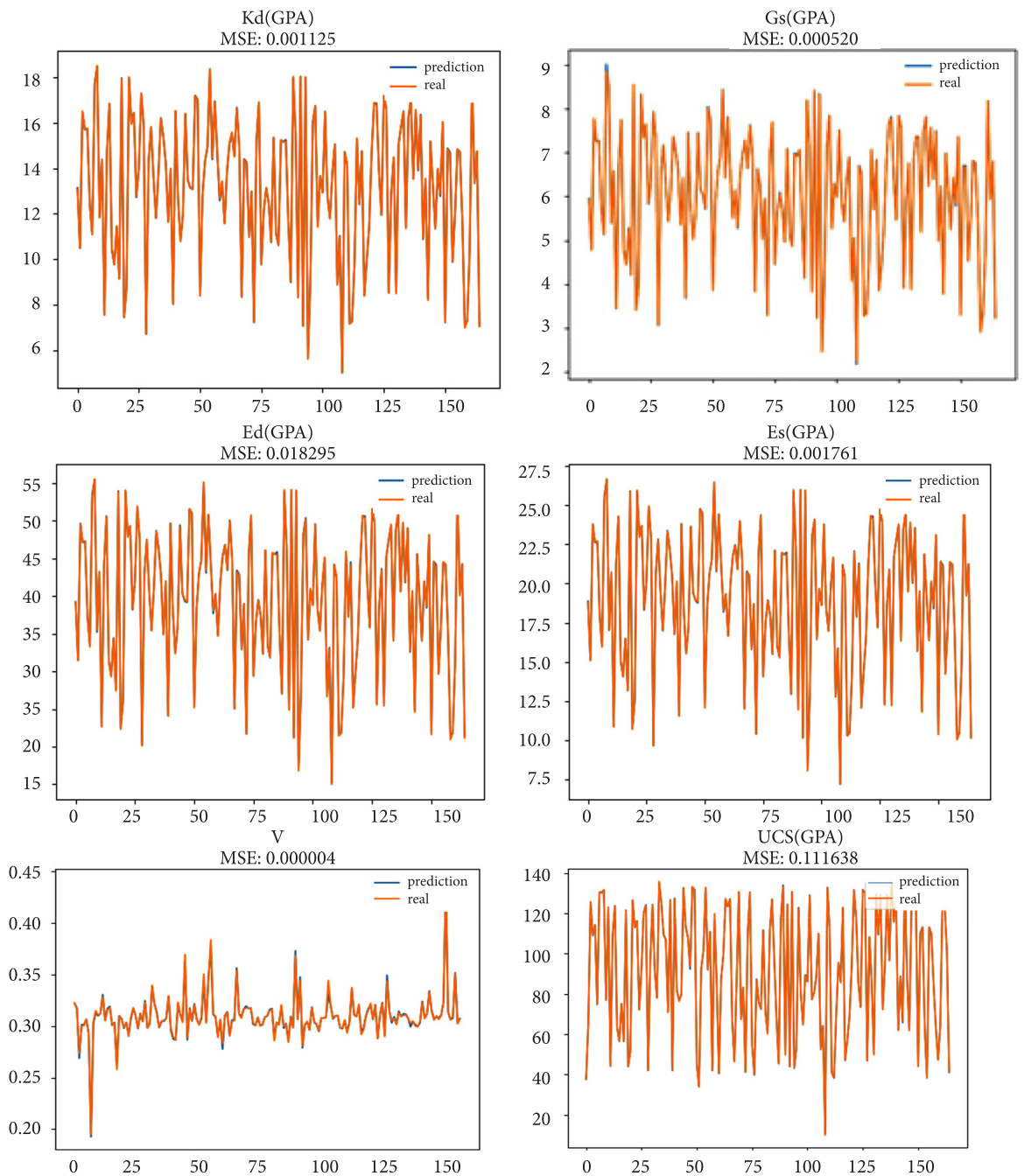

Figure 17. Estimation of elastic properties of rock by artificial neural network

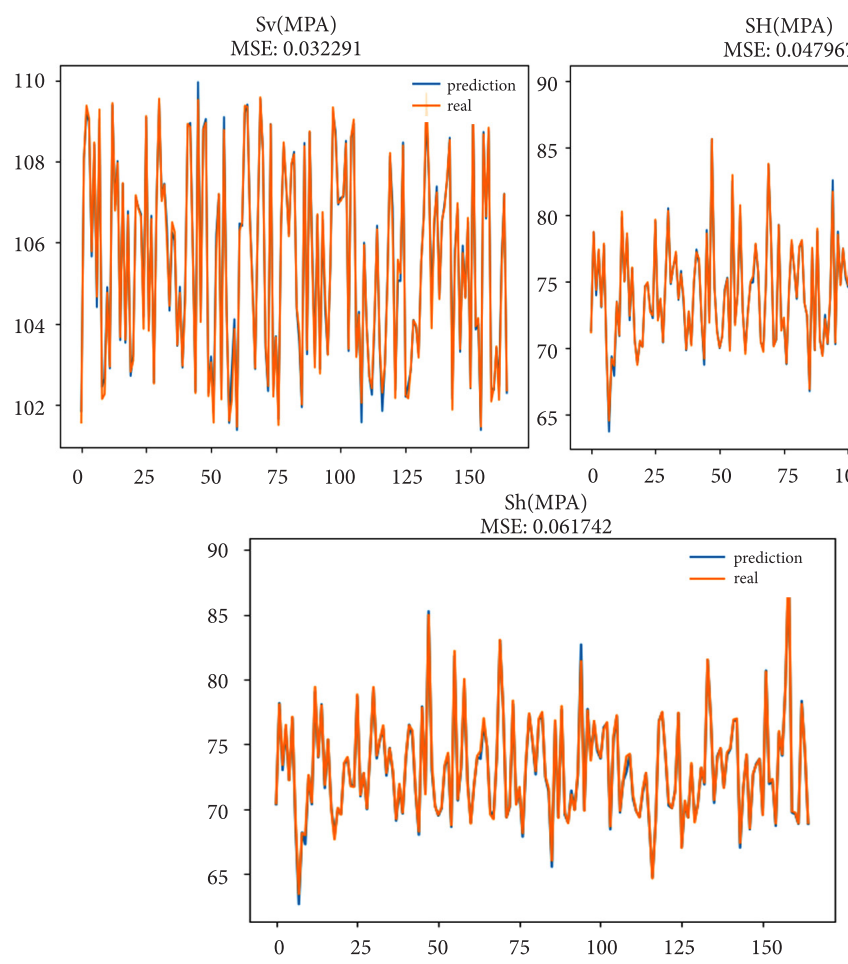

Figure 18. Estimation of deep stress field by artificial neural network 
estimation of vertical stress, the input parameter is the depth of the other parameters, while for the estimation of horizontal stress, the effect of the petrophysical sonic log is much higher.

\section{Conclusions}

In this paper, the magnitude and direction stresses were determined using the poroelastic method and based on petrophysical data. The result of this method show relative compliance with the stress that was calculated on the basis of the width of the breakout and rock strength. The wellbores affected by these stresses are mostly stable, with no severe and extensive failures. The safe mud weight window was determined based on the estimated stress profiles. This mud window showed that in some depth, the used mud pressure is not appropriate and cause the limited failures.

It should be noted that in the studied field, there are other important factors in causing the failure such as collisions of the drill string with the wellbore, sudden decrease of drilling mud pressure and the presence of fractures.

In this field, the minimum horizontal stress has a direction of NW-SE. The stress is mainly normal and strikeslip in some depth.

An artificial neural network showed a high ability to estimate the elastic modulus of the rock and the stress field. It estimates these parameters with a very small error.

The higher the number of inputs to the neural network, the higher the accuracy of the output of the model. For this reason, petrophysical data is the most useful data in this field.

\section{References}

Aadnøy, B. S. (1990). Inversion technique to determine the insitu stress field from fracturing data. Journal of Petroleum Science and Engineering, 4, 127-141. https://doi.org/10.1016/0920-4105(90)90021-T

Akbar Ali, A. H., Brown, T., Delgado, R., Lee, D., Plumb, D., Smirnov, N., Marsden, J. R., Prado-Velarde, E., Ramsay, L., Spooner, D., Stone, T., \& Stouffer, T. (2003). Watching rocks change - mechanical earth modeling. Oilfield Review, 15(1), 22-39.

Akbar, M., \& Sapru, A. (1994). In-situ stresses in the subsurface of "arabian peninsula" and their affect on fracture's morphology and permeability. Paper presented at the $6^{\text {th }}$ Abu Dhabi International Petroleum Exhibition and Conference.

Al-Ajmi, A. (2006). Wellbore stability analysis based on a new true-triaxial failure criterion (Doctoral dissertation, Sultan Qaboos University, Oman). Retrieved from https://www. researchgate.net/publication/220010370_WELLBORE_STABILITY_ANALYSIS_BASED_ON_A_NEW_TRUE-TRIAXIAL_FAILURE_CRITERION

Ameen, M. S., Smart, B. G. D., Somerville, J., Hammilton, S., \& Naji, N. A. (2009). Predicting rock mechanical properties of carbonates from wireline logs (A case study: Arab-D reservoir, Ghawar field, Saudi Arabia). Marine and Petroleum Geology, 26(4), 430-444.

https://doi.org/10.1016/j.marpetgeo.2009.01.017
Anderson, E. M. (1951). The dynamics of faulting and dyke formation. London: Olivier and Boyd.

Anemangely, M., Ramezanzadeh, A., \& Tokhmechi, B. (2017). Shear wave travel time estimation from petrophysical logs using ANFIS-PSO algorithm: A case study from Ab-Teymour Oilfield. Journal of Natural Gas Science Engineering, 38, 373387. https://doi.org/10.1016/j.jngse.2017.01.003

Anemangely, M., Ramezanzadeh, A., Tokhmechi, B., Molaghab, A., \& Mohammadian, A. (2018a). Development of a new rock drillability index for oil and gas reservoir rocks using punch penetration test. Journal of Petroleum Science Engineering, 166, 131-145.

https://doi.org/10.1016/j.petrol.2018.03.024

Anemangely, M., Ramezanzadeh, A., Tokhmechi, B., Molaghab, A., \& Mohammadian, A. (2018b). Drilling rate prediction from petrophysical logs and mud logging data using an optimized multilayer perceptron neural network. Journal of Geophysics and Engineering, 15(4), 1146-1159.

Azadpour, M., Shad Manaman, N., Kadkhodaie-Ilkhchi, A., \& Sedghipour, M. R. (2015). Pore pressure prediction and modeling using well-logging data in one of the gas fields in south of Iran. Journal of Petroleum Science Engineering, 128, 15-23. https://doi.org/10.1016/j.petrol.2015.02.022

Barton, C. A., Zoback, M. D., \& Burns, K. L. (1988). In-situ stress orientation and magnitude at the fenton geothermal site, New Mexico, determined from wellbore breakouts. Geophysical Research Letters, 15(5), 467-470.

https://doi.org/10.1029/GL015i005p00467

Blanton, T. L., \& Olson, J. E. (1999). Stress magnitudes from logs-effects of tectonic strains and temperature. SPE Reservoir Evaluation and Engineering, 2(1), 62-68. https://doi.org/10.2118/54653-PA

Brudy, M., \& Zoback, M. D. (1999). Drilling-induced tensile wall-fractures: implications for the determination of in-situ stress orientation and magnitude. International Journal of Rock Mechanics and Mining Sciences, 36(2), 191-215. https://doi.org/10.1016/S0148-9062(98)00182-X

Byerlee, J. D. (1978). Friction of rock. Pure and Applied Geophysics, 116, 615-626. https://doi.org/10.1007/BF00876528

Chen, X., Tan, C. P., \& Haberfield, C. M. (1996). Wellbore stability analysis guidelines for practical well design. Paper presented at the SPE Asia Pacific Oil and Gas Conference, Adelaide, Australia. https://doi.org/10.2118/36972-MS

Economides, M. J., Oligney, R., \& Valko, P. P. (2000). Unified fracture design. Alvin Texas, USA: Orsa Press.

Fjaer, E., Holt, R. M., Horsrud, P., Raaen, A. M., \& Risnes, R. (2008). Petroleum related rock mechanics (2 $2^{\text {th }}$ ed.). Amsterdam: Elsevier.

Gaarenstroom, L., Tromp, R. A. J., De Jong, M. C., \& Brandenburg, A. M. (1993). Overpressures in the Central North Sea: implications for trap integrity and drilling safety. Petroleum Geology Conference Series, 4, 1305-1313.

Haimson, B., \& Fairhurst, C. (1967). Initiation and extension of hydraulic fractures in rocks. SPE Journal, 7(3), 310-318.

Haimson, B. C., \& Herrick, C. G. (1985). In situ stress evaluation from borehole breakouts: experimental studies. Paper presented at the $26^{\text {th }}$ US Symposium on Rock Mechanics, Rapid City, South Dakota, USA.

Iverson, W. P. (1996). Log-derived stress in anisotropic formations. The Log Analyst, 37(5), 33-40

Khosravanian, R., \& Aadnoy, B. S. (2016). Optimization of casing string placement in the presence of geological uncertainty in oil wells: offshore oilfield case studies. Journal of Petroleum Science Engineering, 142, 141-151. https://doi.org/10.1016/j.petrol.2016.01.033 
Kidambi, T., \& Kumar, G. S. (2016). Mechanical Earth Modeling for a vertical well drilled in a naturally fractured tight carbonate gas reservoir in the Persian Gulf. Journal of Petroleum Science Engineering, 141, 38-51. https://doi.org/10.1016/j.petrol.2016.01.003

Kirsch, G. (1898). Die theorie der elastizitat und die bedurfnisse der festigkeitslehre. Zeitschrift des Vereins Deutscher Ingenieure, 42(29), 797-807.

Klimentos (Schlumberger), T. (2005). Optimizing drilling performance by wellbore stability and pore-pressure evaluation in deepwater exploration. Paper presented at the International Petroleum Technology Conference, Doha, Qatar. https://doi.org/10.2523/IPTC-10933-MS

Mohiuddin, M. A., Khan, K., Abdulraheem, A., Al-Majed, A., \& Awal, M. R. (2007). Analysis of wellbore instability in vertical, directional, and horizontal wells using field data. Journal of Petroleum Science Engineering, 55, 83-92. https://doi.org/10.1016/j.petrol.2006.04.021

Morita, N., Fuh, G. F., \& Black, A. D. (1996). Borehole breakdown pressure with drilling fluids-II. Semi-analytical solution to predict borehole breakdown pressure. International Journal Rock Mechanics and Mining Sciences \& Geomechanics Abstracts, 33(1), 53-69.

https://doi.org/10.1016/0148-9062(95)00029-1
Najibi, A. (2012). Correlation between rock mechanical parameters and petrophysical data at Kupal oil field and its impact on wellbore stability analysis (Unpublished doctoral dissertation). Persia.

Najibi, A. R., Ghafoori, M., Lashkaripour, G. R., \& Asef, M. R. (2015). Empirical relations between strength and static and dynamic elastic properties of Asmari and Sarvak limestones, two main oil reservoirs in Iran. Journal of Petroleum Science Engineering, 126, 78-82. https://doi.org/10.1016/j.petrol.2014.12.010

Zoback, M. D. (2007). Reservoir geomechanics. Cambridge: Cambridge University Press. https://doi.org/10.1017/CBO9780511586477

Zoback, M. D., \& Healy, J. H. (1984). Friction, faulting, and "in situ" stresses. Annals Geophysics, 2, 689-698.

Zoback, M. D., Barton, C. A., Brudy, M., Castillo, D. A., Finkbeiner, T., Grollimund, B. R., Moos, D. B., Peska, P., Ward, C. D., \& Wiprut, D. J. (2003). Determination of stress orientation and magnitude in deep wells. International Journal of Rock Mechanics and Mining Sciences, 40, 1049-1076. https://doi.org/10.1016/j.ijrmms.2003.07.001 